\title{
A New Automotive Air Conditioning System Simulation Tool Developed in MATLAB/Simulink
}

\author{
Tibor Kiss and Lawrence Chaney \\ National Renewable Energy Laboratory \\ John Meyer \\ Visteon Corporation
}

\begin{abstract}
Accurate evaluation of vehicles' transient total power requirement helps achieving further improvements in vehicle fuel efficiency. When operated, the air-conditioning (A/C) system is the largest auxiliary load on a vehicle, therefore accurate evaluation of the load it places on the vehicle's engine and/or energy storage system is especially important. Vehicle simulation models, such as "Autonomie", have been used by OEMs to evaluate vehicles' energy performance. However, the load from the $\mathrm{A} / \mathrm{C}$ system on the engine or on the energy storage system has not always been modeled in sufficient detail. A transient $\mathrm{A} / \mathrm{C}$ simulation tool incorporated into vehicle simulation models would also provide a tool for developing more efficient $\mathrm{A} / \mathrm{C}$ systems through a thorough consideration of the transient $\mathrm{A} / \mathrm{C}$ system performance. The dynamic system simulation software MATLAB/Simulink ${ }^{\circledR}$ is frequently used by vehicle controls engineers to develop new and more efficient vehicle energy system controls. A MATLAB/Simulink-based transient A/C system simulation model is easier to incorporate into MATLAB/Simulink-based vehicle simulation software; therefore, the availability of a transient $\mathrm{A} / \mathrm{C}$ system simulation tool developed in the MATLAB/Simulink platform is important.

NREL has recently developed an $\mathrm{A} / \mathrm{C}$ simulation tool to address these needs. This paper describes in detail the modeling methods used for this new simulation tool. Comparison with measured data is provided to demonstrate the validity of the model. The agreement between simulation and measurement was shown to be good on both the component and system level. The capabilities of the model are also demonstrated by the example of simulating the SC03 cycle.
\end{abstract}

CITATION: Kiss, T., Chaney, L. and Meyer, J., "A New Automotive Air Conditioning System Simulation Tool Developed in MATLAB/Simulink," SAE Int. J. Passeng. Cars - Mech. Syst. 6(2):2013, doi:10.4271/2013-01-0850.

\section{INTRODUCTION}

When operated, the air-conditioning $(\mathrm{A} / \mathrm{C})$ system is the largest auxiliary load on a vehicle. A/C loads account for more than $5 \%$ of the fuel used annually for light-duty vehicles in the United States [1]. A/C loads can significantly impact electric vehicle (EV), plug-in hybrid electric vehicle (PHEV), and hybrid electric vehicle (HEV) performance. Mitsubishi reports that the range of the i-MiEV can be reduced by as much as $50 \%$ on the Japan $10-15$ cycle when the $\mathrm{A} / \mathrm{C}$ is operating [2]. The advanced powertrain research facility at Argonne National Laboratory has reported a nearly $20 \%$ reduction in range in the Nissan Leaf operating on the UDDS cycle. A hybrid vehicle tested at NREL showed 22\% lower fuel economy with the $\mathrm{A} / \mathrm{C}$ on [3] . Increased cooling demands from the battery thermal management system in an EV may impact the A/C system. Heavy-duty vehicles also need a tool to evaluate the impact of $\mathrm{A} / \mathrm{C}$ on both "down-the- road" and idle conditions. Cabin climate conditioning is one of the primary reasons for operating the main engine in a long-haul truck during driver rest periods. In the United States, long-haul trucks (trucks that travel more than 500 miles per day) use 838 million gallons of fuel annually for rest period idling [4]. A flexible open-source analysis tool is needed to assess the $\mathrm{A} / \mathrm{C}$ system's impact on advanced vehicles. The industry has expressed a need for both a standalone $\mathrm{A} / \mathrm{C}$ system model as well as an $\mathrm{A} / \mathrm{C}$ model that can co-simulate with a vehicle simulator such as Autonomie [5]. This model expands the capability of vehicle simulation tools, including Autonomie, and addresses industry needs.

The $\mathrm{A} / \mathrm{C}$ system contains complex flow, thermodynamics, and heat transfer. On the refrigerant side, the flow is transient and both compressible and two-phase. Calculating refrigerant properties near the phase transitions can also be computationally difficult. Air flow through the condenser can vary widely depending on vehicle speed and condenser fan 
speed. The heat transfer in the heat exchangers is a very complex process mainly addressed by complex correlations based on measured data. These correlations sometimes reduce the stability of the code. The effects of humidity are difficult to account for, not only in the model but also for the experimental data necessary to calibrate the code. A cabin model is also needed to provide a realistic load on the evaporator. The cabin model must consider all the major pathways of heat transfer into the cabin, including solar and convective loads from the environment, heat from the engine compartment, and sensible and latent heat loads in the air stream. Realistic control methods similar to ones actually used in automotive $\mathrm{A} / \mathrm{C}$ systems also have to be implemented. The cycling of the compressor can introduce quick transients that are sometimes difficult to handle by the numerical solver. The simulation model also has to be fast enough for the purpose of evaluating vehicle power performance and/or the design of $\mathrm{A} / \mathrm{C}$ systems and their controls.

There are numerous challenges in developing a suitable automotive A/C system simulation tool. Some examples of previously developed non-commercial full system-level simulation include $[\underline{6}, \underline{7}, \underline{8}]$. However, to the best of our knowledge, none of them is both developed in the widely used dynamic system simulation platform MATLAB/ Simulink (which is helpful for controls engineers) and available to the public at the same time. Commercially available software tends to be very expensive, and typically, their accuracy for predicting the transient processes is difficult to assess based on available documentation. The simulation model subject of this paper addresses these issues. Also, with the model being built on the MATLAB/Simulink platform, most of the inner workings of the model are visible to the user, and the user has considerable freedom to modify the model to better represent their specific $\mathrm{A} / \mathrm{C}$ system hardware and controls. Only the source codes for some of the basic building blocks of the model remain inaccessible to the user.

\section{SELECTING THE MODELING METHOD}

Numerically, the most difficult part is modeling the twophase refrigerant flow circuit. A number of different methods have been used in the past, and the selection of which method to use was based on the intended purpose of the simulation model.

With the transient nature of automotive $\mathrm{A} / \mathrm{C}$ systems, the authors thought it was most important that the modeling method capture the transient processes accurately and robustly, even if model execution speed was compromised. The model should be robust for fast transients such as compressor cycling. It should also accurately predict refrigerant redistribution after shut-down and after start-up. It has to conserve mass accurately during simulations of long test cycles.
Another desirable feature of the model was that it should be versatile enough that various complex heat transfer correlations can be programmed into the main algorithm relatively easily. Finally, the model formulation had to be one that was well suited for the simulation modeling platform, MATLAB/Simulink.

The authors decided to use the finite volume formulation for calculating the refrigerant flow. The finite volume formulation is well suited for accurate conservation of mass momentum and energy. Also, in the finite volume formulation, immediately after each step of the integrator, the state variables and the velocity are readily available. Then, heat transfer rates even with the more complex methods can be calculated explicitly. Finally, Simulink is geared toward solving ordinary differential equation systems and, in the finite volume formulation, the problem is established as a set of ordinary differential equations. Therefore, this formulation is very well suited for Simulink.

Challenges were expected with the "stiff" nature of this modeling method, especially in the condenser where pure liquid is present.

\section{DESCRIPTION OF THE MODEL}

The transient $\mathrm{A} / \mathrm{C}$ simulation model consists of two main sub-models that include the cooling circuit model and the cabin model. In the cooling circuit model, the larger volumes containing refrigerant, such as the accumulator, the receiver/ dryer, and the headers of the heat exchangers, are modeled with the zero-dimensional volume simulation block (0-D volume block). The refrigerant pipes and the flat tubes / plates of the heat exchangers are modeled with various versions of the one-dimensional pipe simulation block (1-D pipe block). The general structure of the model on the refrigerant side is a network of 1-D pipe blocks connected to each other with $0-\mathrm{D}$ volume blocks.

Using the $0-\mathrm{D}$ volume and the 1-D pipe blocks, models of various multi-pass multi-row compact heat exchangers can be created relatively easily. Models for other $\mathrm{A} / \mathrm{C}$ system components, such as the compressor and the thermostatic expansion valve, were incorporated with the goal of maintaining sufficient accuracy and acceptable execution speed. The model currently uses R134a exclusively as the refrigerant. However, other refrigerants can be used if the user builds the required property tables in a specified text file format.

In the following sections, the 0-D volume block, the 1-D pipe block and various other modeling blocks are described in detail.

\section{The 0-D Volume Simulation Block}

The 0-D volume blocks serve as models for real volumes in the system as well as the connectors between the 1-D pipe blocks. In the 0-D volume block, the sum of the incoming refrigerant mass flow rates minus the sum of the outgoing refrigerant mass flow rates determine the time derivative of 
the refrigerant mass in the volume, and the sum of the incoming refrigerant enthalpy flow rates minus the sum of the outgoing refrigerant enthalpy flow rates plus the net heat transfer to the volume determine the time derivative of the internal energy in the volume. Note that when saturated conditions exist in the 0-D volume block, saturated liquid, saturated vapor, or a saturated mix can be selected for the output flow, according to the system component represented by the simulation block. An accumulator, for example, is physically designed to only let out saturated vapor.

Since internal energy and mass are the state variables for the simulation, all other material properties are looked up from two-dimensional tables based on specific internal energy and density. Such lookup tables provide the best numerical performance as no iteration on properties is required.

\section{The 1-D Pipe Simulation Block}

In all versions of the 1-D pipe simulation blocks, on the refrigerant side, equations for conservation of mass, momentum and energy are solved through a finite volume method. As with the 0-D volume block, all refrigerant material properties are obtained from two-dimensional tables based on specific internal energy and density. The evaluation of heat transfer between the pipe wall and the refrigerant, and between the pipe wall and air is incorporated through local heat transfer coefficient correlations. The effectiveness-NTU method is applied on the air side, which ensures that the exit air temperature does not overshoot the wall temperature. The time derivative of the wall temperature is calculated from the net heat flow rate to the wall. Therefore, the thermal capacity of the wall has been accounted for. However, the temperature drop across the pipe wall has not been accounted for. It was determined that the introduced error is small for the relatively thin walls of the flat tubes / plates found in typical compact heat exchangers in an $\mathrm{A} / \mathrm{C}$ system. In the direction of air flow, the temperature of the wall is constant. From the applied finite volume method, it is inherent that in the 1-D pipe simulation block, refrigerant flow can take place in both directions.

The simplest version of the 1-D pipe simulation block is used to model the refrigerant lines connecting the various $\mathrm{A} / \mathrm{C}$ system components. Here a circular pipe is simulated in a perpendicular cross-flow of air. For these connecting lines, the effects of the relative humidity and condensation of water on the pipe are neglected.

More complex versions of the 1-D pipe simulation block are used for simulating the refrigerant and air flow and heat exchange process for the flat tubes of the condenser and plates of the evaporator. These 1-D pipe model block versions include the options of multiple "parallel channels" on the refrigerant side and more complex fin geometry on the external air flow side. Humidity in the air and condensation of water from air is accounted for. It is assumed that the refrigerant flow properties inside the parallel channels are identical. Also, the wall/fin temperatures in the direction of the air flow are assumed to be constant. This is certainly an approximation, but one necessary to maintain reasonable simulation execution speed.

The finite volume formulation that is used for the refrigerant flow is a conservative method in the sense that the mass, momentum and energy are conserved very accurately. For the air flow, there are no conservative terms and the flow is described with purely algebraic equations.

\section{Refrigerant-side equations}

The general control volume equations for the conservation of mass, momentum and energy as presented in [9] are used as a starting point. The general control volume equations are then written for one dimension, as all flow variables are assumed to change only in the direction of refrigerant flow, and for finite volumes, that is small volumes, over which the flow variables can be considered uniform. Note that the refrigerant is in thermodynamic equilibrium in the finite volumes, and velocity "slip" between the liquid and the vapor phase is not factored in. The refrigerant is also considered homogeneous, that is, all flow properties, including liquid and vapor phase volume ratios, are the same everywhere within the finite volume. Finally, the effects of gravity are neglected.

\section{Conservation of mass}

We start out from the conservation of mass ([9], Eq. 3.3.1):

$$
0=\frac{\delta}{\delta t} \int_{c v} \rho d V+\int_{c s} \rho \underline{v} \cdot \underline{d A},
$$

where $\rho$ is the refrigerant density, $\underline{v}$ is the velocity vector, $\int_{c v}$ $d V$ is the volume integral and $\int_{c s} \frac{d A}{}$ is the surface integral. The first integral on the right is the mass in the finite volume, and then for the one dimensional flow for the finite volume:

$$
\frac{d m}{d t}=\rho_{\text {in }} A v_{\text {in }}-\rho_{\text {out }} A v_{\text {out }},
$$

where $A$ is the pipe cross sectional area, and the in / out subscripts are for inlet and outlet boundaries of the finite volume, defined also as the left-side and right-side boundaries, respectively, as we use the convention that the positive flow is from left to right.

\section{Conservation of momentum}

The conservation of momentum written for a control volume ([9], Eq.3.3.8):

$$
\sum F=\frac{\partial}{\partial t} \int_{c v} \rho \underline{v} d V+\int_{c S} \rho \underline{v v} \cdot \underline{d A},
$$

where $\Sigma F$ is the sum of all forces including shear and pressure forces on the control volume. We define the first integral on the right side as the linear momentum, $I$. For finite 
volume formulation for one-dimensional flow the following can be written:

$$
\frac{d I}{d t}=\rho_{\text {in }} A v_{\text {in }}^{2}-\rho_{\text {out }} A v_{\text {out }}^{2}+\left(p_{\text {in }}-p_{\text {out }}\right) A+F_{\text {wf }},
$$

where $p_{\text {in }}$ and $p_{\text {out }}$ are the pressures on the inlet and outlet boundary, respectively, and $F_{w f}$ is the force from wall friction. For the wall friction force, a version of the DarcyWeisbach formula ([9], Eq.5.8.7) was used in which the wall friction factor was obtained with the Hagen-Poisseuille equation ([9], Eq. 5.10.12) for laminar flow and from a modified version of the Colebrook equation ([9], Eq. 5.10.13) for turbulent flow. This latter equation does take into account the effect of the relative roughness of the pipe wall. These equations are used for both single and two-phase flow. In the two-phase region, the viscosity was obtained as the quality weighted average of the saturated liquid and saturated vapor viscosity. A user-adjustable calibration coefficient was also implemented.

\section{Conservation of energy}

The energy equation written for a control volume ([9], Eq. 3.3.6):

$$
\frac{\delta Q_{H}}{\delta t}-\frac{\delta W_{s}}{\delta t}=\frac{\partial}{\partial t} \int_{c v} \rho e d V+\int_{c S}\left(\frac{p}{\rho}+e\right) \rho \underline{v} \cdot \underline{d A},
$$

where $\frac{\delta Q_{H}}{\delta t}$ is the rate of heat addition, $\frac{\delta W_{S}}{\delta t}$ is the rate of work done by the system via shear forces, and $e$ is the total energy per unit mass: $e=u+\frac{v^{2}}{2}$, where $u$ is the specific internal energy and $v$ is the velocity. Note that all components other than the internal and kinetic energy have been neglected. This equation also assumes no other boundary work than that on the inflow and outflow surfaces. We define $E$ as the first integral on the right side, which is the total energy in the finite volume. Then, assuming 1-D flow, no shear force work, and heat addition strictly through the pipe wall (no conductive heat transfer through inflow/outflow boundaries), the following equation can be written for each control volume in the pipe (also will be called as a "segment" of the pipe):

$$
\begin{gathered}
\frac{d E}{d t}=A v_{\text {in }}\left(p_{\text {in }}+u_{\text {in }} \rho_{\text {in }}+\rho_{\text {in }} \frac{v_{\text {in }}^{2}}{2}\right)- \\
A v_{\text {out }}\left(p_{\text {out }}+u_{\text {out }} \rho_{\text {out }}+\rho_{\text {out }} \frac{v_{\text {out }}^{2}}{2}\right)+Q_{\text {wr }},
\end{gathered}
$$

where $Q_{w r}$ is the heat transfer rate from the pipe wall to the refrigerant flowing inside the pipe segment. Note that $Q_{w r}$ can be written as

$$
Q_{w r}=\bar{h} A_{i}\left(T_{w}-T\right),
$$

where $\bar{h}$ is the average heat transfer coefficient over the pipe segment, $A_{i}$ is the inside area of the pipe segment wall, and $T_{w}$ is the pipe segment average wall temperature. To calculate $\bar{h}$, the Dittus-Boelter equation ([10], Eq. 8.58) and/or the Chen correlation [11] is used. Note that the transition points between the single-phase and two-phase regions along the length of the pipe need to be determined for the proper application of the heat transfer rate correlations. These transition points are easily obtained from the mass and total energy, which are simulation state variables and therefore available in the finite volumes at the start of each time step.

\section{Spatial discretization}

The spatial discretization was implemented as shown in Fig. 1. Note that a "staggered" grid was used. While the control volumes were defined for mass and energy as the volumes shown between the $0-1,1-2,2-3, \ldots$ location indexes (Type 1 finite volumes), for the linear momentum they were defined as the volumes between the $0-0 \mathrm{a}, 0 \mathrm{a}-1 \mathrm{a}, 1 \mathrm{a}-2 \mathrm{a}, 2 \mathrm{a}-3 \mathrm{a}$, ... location indexes (Type 2 finite volumes). So in fact there are two sets of finite volumes, one set for the mass and energy equations, and one set for the momentum equations. This staggered spatial discretization method had to be used to avoid instability problems. Other authors have also used this method [12], perhaps for the same reason. Note that the first and last Type 2 finite volumes (finite volumes for linear momentum) are "half" size compared to the rest of the ones in the middle of the pipe.

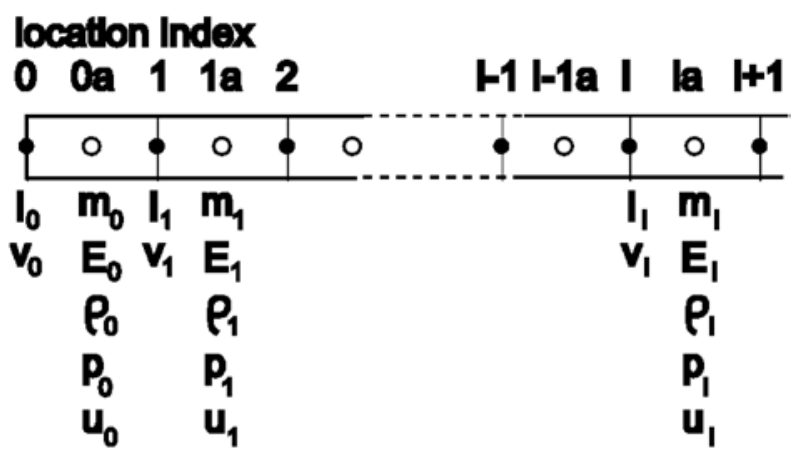

Fig. 1. Spatial resolution for the finite volume formulation

To implement the conservation equations, the variables $\rho_{\text {in }}, \rho_{\text {out }}, p_{\text {in }}, p_{\text {out }}, v_{\text {in }}, v_{\text {out }}, u_{\text {in }}$ and $u_{\text {out }}$ (the density, pressure, velocity and specific internal energy on the finite volume boundaries, respectively) have to be obtained from the conserved variables $m, I$ and $E$ (the mass, the momentum and energy, in the finite volumes, respectively). The conserved variables are also the simulation state variables that are available immediately after the integrator advances one time step. From the definition of these variables:

$$
\rho=m / V
$$




$$
\begin{gathered}
v=I / m \\
u=E / m-v^{2} / 2 \\
p=p(\rho, u)
\end{gathered}
$$

Then a simple first-order interpolation of the flow variables on the finite volume boundaries was implemented. For example, for the conservation of mass, the density and velocity on the left-side boundary of the $i^{\text {th }}$ Type 1 finite volume is estimated as

$$
\begin{gathered}
\rho_{\text {in }}=\left(\rho_{i-1}+\rho_{i}\right) / 2 \\
v_{\text {in }}=v_{i},
\end{gathered}
$$

and for the conservation of momentum equation, the density and velocity on the left-side boundary of the $i^{\text {th }}$ Type 2 finite boundary are estimated as

$$
\begin{gathered}
\rho_{\text {in }}=\rho_{i-1}, \\
v_{\text {in }}=\left(v_{i-1}+v_{i}\right) / 2 .
\end{gathered}
$$

Note how the interpolations are different between conservation of mass and conservation of linear momentum due to the staggered Type 1 and Type 2 finite volumes.

\section{Applying the boundary conditions}

In this section we discuss the boundary conditions of the overall computational domain, that is, the left-side boundary of the first finite volume and the right-side boundary of the last finite volume. Flow variables on these surfaces cannot be calculated the same way as on the boundaries between two finite volumes because they are attached to $0-\mathrm{D}$ volume blocks. The boundary conditions have to be treated differently depending on whether inflow or outflow was present on the boundary, determined by the sign of the linear momentum, $I$. For the inflow, conditions from the connected 0 -D volume block could be applied readily to obtain the boundary conditions. Calculating the outflow boundary conditions is more challenging as there are various ways of extrapolating flow variables to the boundary and some of these methods did not work well regarding stability, accuracy or speed. In the end, the following method was found to work well. To calculate the boundary velocity, the linear momentum in the Type 2 boundary finite volume (available as state variable) was divided by one-half the mass in the Type 1 boundary finite volume. The boundary pressure for outflow was simply the pressure in the connected 0-D volume. The specific internal energy on the boundary was extrapolated linearly from the first two regular Type 1 finite volumes next to the boundary. Finally, once the boundary internal energy and pressure were known, the boundary density could be calculated through an iterative process using the pressure vs. specific internal energy and density tables.

\section{Air-side equations}

The heat transfer rate from the air flow to the wall of a pipe segment can be written as

$$
Q_{a w}=\bar{h}_{a} \cdot A_{t o t} \cdot\left(T_{a}-T_{w}\right),
$$

where $\bar{h}_{a}$ is the average air-to-wall heat transfer coefficient in the pipe segment, $T_{w}$ is the pipe segment average wall temperature, and $A_{t o t}$ is the total surface available for heat transfer on the air side in the pipe segment.

The air-side equations are different for the various versions of the 1-D pipe model blocks. For the transport refrigerant pipes, the correlation for heat transfer on a pipe in a perpendicular cross-flow of air was implemented according to Eq. 7.53 of [10]. For air-side heat exchange on the finned heat exchangers, the Chang correlation [13] was implemented. It is noted that although the Chang correlation did not incorporate the effects of humidity and condensation, we still apply this correlation for moist air.

Chang proposed a detailed and a simplified correlation, where the local heat transfer coefficient is calculated by using a correlation for the Colburn $\mathrm{j}$-factor, $j$. The simplified correlation is

$$
j=0.425 R e_{L_{p}}^{-0.496},
$$

where $R e_{L p}$ is the Reynolds number based on the louver pitch, $L_{p}$ (see Fig. 2). The more complex version of the Chang correlation incorporates a dependency on louver angle, fin length, tube depth, louver length, tube pitch and fin thickness. The model user can switch between the simplified and more detailed correlation versions. The details of how the heat transfer coefficient can be obtained from the Colburn $j$ factor can be found in [10] p.534.

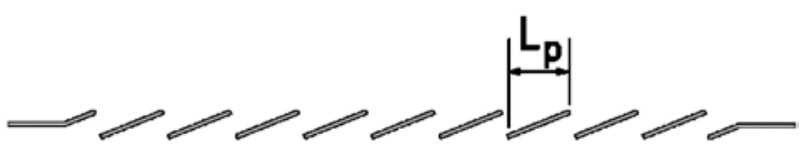

Fig. 2. Louver pitch used in the Chang correlation

The local heat transfer coefficient, $h_{a}$ obtained by either the simpler or the more complex Chang correlation has to be adjusted to get an average heat transfer coefficient, $\bar{h}_{a}$ by incorporating the effects of the fins not being able to maintain the same temperature as the flat tube itself

$$
\bar{h}_{a}=\eta_{0} \cdot h_{a},
$$


where $\eta_{0}$ is the fin effectiveness, which can be written as

$$
\eta_{0}=1-\frac{A_{f}}{A_{\text {tot }}} \cdot\left(1-\eta_{f}\right)
$$

Here $A_{t o t}$ is the total area for heat transfer, $A_{f}$ is the finned area available for heat transfer and $\eta_{f}$ is the fin efficiency. The fin efficiency for the straight fins between two flat tubes / plates can be expressed as ([10], Eq.11.4):

$$
\eta_{f}=\tanh (m L) /(m L),
$$

where $L$ is the half fin length, $m=(2 h / k t), k$ is the thermal conductivity of the fin material, and $t$ is the fin material thickness.

With that, the equation (16) can be evaluated, but it will be accurate only as long as the temperature change of the air across the flat tube is small relative to the difference between the incoming air temperature and the flat tube wall temperature. In general that cannot be assumed and therefore the effectiveness-NTU method is used as applied to a parallel flow heat exchanger ([10], Eq.11.29a):

$$
\varepsilon=\frac{1-\exp \left\{-\mathrm{NTU}\left[1+C_{r}\right]\right\}}{1+C_{r}},
$$

where $C_{r}$ is the ratio of the lower and the higher heat capacity rates:

$$
C_{r}=\frac{C_{\text {low }}}{C_{\text {high }}}
$$

where the heat capacity rate is the mass flow rate of the medium participating in the heat transfer times its constant pressure specific heat. Because the wall temperature is constant, the refrigerant side can be represented by infinitely large heat capacity flow and heat transfer rate that ensures constant metal temperature along the air flow direction. Therefore, in our special case $C_{r}$ approaches zero, and the above equation simplifies to

$$
\varepsilon=1-\exp (-N T U) .
$$

Furthermore, assume that the heat transfer takes place from the air to the flat tube / plate wall. Then

$$
\varepsilon=\frac{T_{a, i}-T_{a, o}}{T_{a, i}-T_{w}}
$$

can be written ([10], Eq. 11.26), where the subscripts $a, w, i$ and $o$ mean air, wall, in and out, respectively. Finally, per [10], Eq. 11.25,

$$
N T U=\frac{U \cdot A}{C_{l o w}}=\frac{\bar{h}_{a} \cdot A}{\dot{m}_{a} \cdot C_{p, a}},
$$

where $\dot{m}_{a}$ is the air mass flow rate and $C_{p, a}$ is the constant pressure specific heat for the incoming "wet" air, and after $U$ was replaced with $\bar{h}_{a}$ justified by an infinitely large heat capacity flow rate assumed on the refrigerant side. Also, it can be easily shown that

$$
\dot{m}_{a} \cdot C_{p, a}=\dot{m}_{a} \cdot\left(C_{p, a d r y}+\omega C_{p, w}\right),
$$

where $C_{p, a d r y}$ and $C_{p, w}$ are the constant pressure specific heats for dry air, and water vapor, respectively, and $\omega$ is the absolute humidity. Then, from the above three equations, $T_{a, o}$ can be expressed as

$$
\begin{aligned}
& T_{a, o}=T_{a, i}+\left(T_{w}-T_{a, i}\right) . \\
& {\left[1-\exp \left(\frac{-\bar{h}_{a} A}{\dot{m}_{a} \cdot\left(C_{p, a d r y}+\omega C_{p, w}\right)}\right)\right] . }
\end{aligned}
$$

The air-to-wall heat transfer rate now can be obtained as

$$
Q_{a w}=\left(\dot{m}_{a} \cdot C_{p, a d r y}+\dot{m}_{w} \cdot C_{p, w}\right) \cdot\left(T_{a, o}-T_{a, i}\right),
$$

where $\dot{m}_{w}$ is the mass flow rate of the water vapor carried by the wet air. The result would be the same if we had assumed the heat transfer to take place from the flat tube to the air.

At this point the issue of condensation needs to be addressed. Water vapor condensation in the air flowing through the evaporator has a significant effect on the temperature and relative humidity of the wet air leaving the evaporator; therefore, it needs to be accounted for. In the condenser, there is no water condensation, but the relative humidity still has some effect on the results. The same airside model is used for both evaporator and condenser. When used for the condenser or for an evaporator seeing low humidity incoming air, the majority of condensation-related calculations do not get executed; therefore, the performance penalty is insignificant compared to using a dedicated noncondensation pipe model.

Mass flow rate, temperature, and the relative humidity of the incoming wet air for each pipe segment are input variables. The air flow velocity is calculated using the minimum area for air flow inside the heat exchanger, which is an input parameter.

The air-side heat transfer equations are solved for each segment of the pipe. First, the heat transfer rate is calculated as it would be without condensation. The wet air enthalpy is reduced using the heat transfer rate and an air-out temperature is calculated. The partial pressure of the water vapor in the exit wet air is calculated with the exit pressure, exit temperature and the incoming relative humidity. The saturated water vapor pressure is also calculated for the exit air temperature. If the saturated water vapor pressure is higher than the exit air water vapor partial pressure, then 
there is no condensation. In this case all previously calculated properties will be valid, and the calculation can proceed to the next pipe segment. If the saturated water vapor pressure is lower than the exit air water vapor partial pressure, condensation of water does take place, and the flow properties have to be recalculated for the pipe segment considering condensation. The algorithm for condensation conditions assumes that the exiting atmospheric air is saturated with water vapor, and this exit air-vapor mix is at the same temperature as the condensed water. The algorithm then invokes an iteration on the exit wet air temperature, while the heat transfer to the heat exchanger wall is still assumed to be the same as it would be without condensation. It is not known to the authors how much error this assumption introduces. Other treatment of condensation would involve much more complicated heat transfer equations that incorporate the presence of a liquid water layer over the heat exchanger surfaces.

Once the exit wet air temperature is obtained, all other air flow properties can easily be calculated for the current pipe segment. Next, the same process will be applied to all the remaining pipe segments.

\section{Parallel channels}

In order to model a typical condenser configuration, multiple "parallel" channels for refrigerant flow are allowed in a 1-D pipe block. These channels are identical in terms of refrigerant flow. Because the wall temperature is assumed constant within a pipe segment, the wall-to-refrigerant heat transfer rate is also identical in the parallel channels. Therefore, the refrigerant in and out mass flow rates and the wall-to-refrigerant heat transfer rates for a single parallel channel are simply multiplied by the number of parallel channels in the flat tube to get the aggregate numbers for the entire flat tube.

\section{Coupling the air and refrigerant sides}

The air and refrigerant-side equations can be solved on their own separately, because the two sets of equations are not algebraically coupled. The pipe wall temperature, $T_{w}$, appears in both sets of equations, but it is a simulation state variable, which means its value is obtained as a result of an integration step, not from algebraic equations. Therefore, it is available at the beginning of each time step to calculate the heat transfer rates from the air to the pipe wall and from the pipe wall to the refrigerant.

It is assumed that the thermal resistance of the wall is zero. In other words, the inner and outer surfaces of the pipe wall are at the same temperature. This is typically a good approximation for compact heat exchangers as they use thin walls.

The equation for the wall temperature comes from the conservation of energy, which states that the net heat flux into the wall segment is stored as thermal energy in the wall segment:

$$
Q_{a w}-Q_{w r}-\frac{d Q_{x}}{d x} \cdot \Delta x=C_{p w} * \Delta m * \frac{d T_{w}}{d t},
$$

where $Q_{a w}$ is the heat transfer rate from air to the wall, $Q_{w r}$ is the heat transfer rate from the wall to the refrigerant, $Q_{x}$ is the heat transfer rate in the pipe wall in the refrigerant flow direction, $C_{p w}$ is the wall material specific heat, and $\Delta m$ is the mass of the wall segment including all the fins. The $\frac{d Q_{x}}{d_{x}} \cdot \Delta x$ term represents the imbalance in conductive heat flow rates from the neighboring wall segments. This equation is written for each pipe segment, and the wall temperature is obtained for each pipe segment.

\section{Heat Exchangers}

Currently, the typical heat exchangers in automotive $\mathrm{A} / \mathrm{C}$ systems are compact heat exchangers with a general structure that can be described as a number of headers, with "passes" between these headers. Nearly all of the heat transfer takes place in the passes. Using conventional terminology, one pass in the condenser consists of a number of flat tubes and one pass in the evaporator consists of a number of plates.

Two versions of the above described 1-D pipe model simulation block, with air-side heat transfer according to the Chang's model, are the basic building block for the heat exchangers in the $\mathrm{A} / \mathrm{C}$ system model. For the version used to model the flat tubes of the condenser, the Dittus-Boelter equation is used on the refrigerant side along the full length of the pass, even across the phase boundaries. In the saturated mix region, quality weighted average of the saturated liquid and saturated vapor properties of the refrigerant are used. This simple model provided a good match with measurement. For the version used to model the plates of the evaporator, on the refrigerant side, the Dittus-Boelter equation [10] is used for the superheat region and the Chen correlation [11] is used for the two-phase region.

In the following paragraphs we use the example of an evaporator; therefore, we will use the term "plates" but the same could be said about the condenser, using the "flat tubes" terminology. With the help of the 0-D volume and 1-D pipe simulation blocks, multiple row and multiple pass heat exchangers can be built relatively easily. The simplest approach is to have one 0-D volume block for each of the headers and connect them with one 1-D pipe model block, each representing one pass. In order to account for the number of plates in each pass, the mass flow rate and heat transfer outputs have to be multiplied by the number of plates in the pass before being routed into the 0 -D volume blocks representing the headers. Therefore, in this approach all the plates in a given pass are treated as identical in terms of their flow and heat transfer. A sub-version of this approach is when the plates in a pass are split up into "sub-passes" depending on which pass is upstream of them in terms of airflow. Each of these sub-passes is then represented with one plate model, and mass flow and heat transfer through a sub- 
pass are once again obtained by mass flow and heat transfer through one plate multiplied by the number of plates in the sub-pass. An example of how this works is shown in Figs. 3a and $\underline{3 \mathrm{~b}}$ for the case of a two-row, two-passes-per-row evaporator for which one of the passes, pass 2, gets the airflow from two different upstream passes. As explained above, this pass is then split up into pass $2 \mathrm{a}$ and pass $2 \mathrm{~b}$, which receive their air flow from passes 3 and 4, respectively. This is the configuration of the evaporator in the current model implementation.

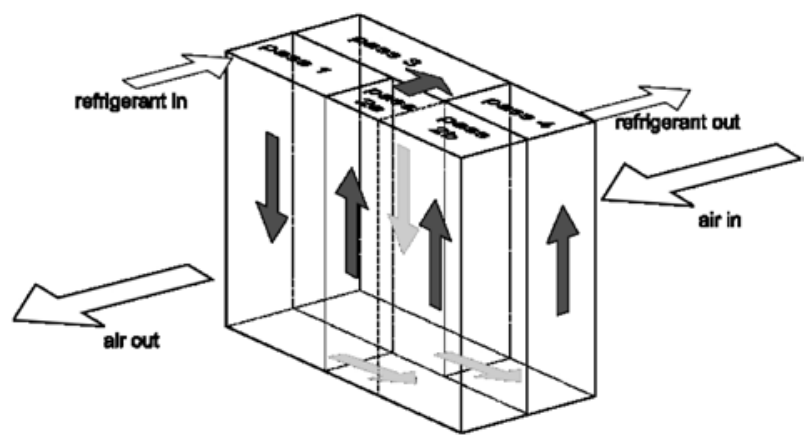

Fig. 3a. Schematic of the implemented evaporator showing air flow dependency of passes

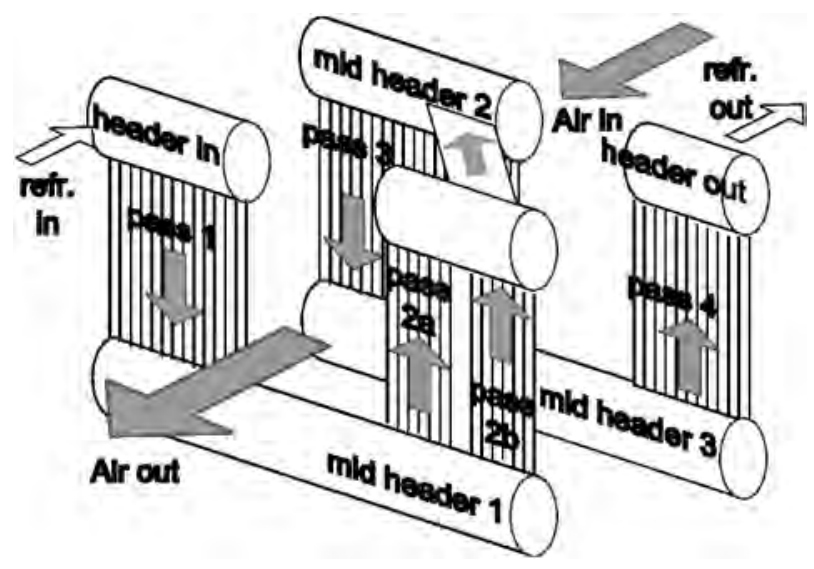

Fig. 3b. The "exploded view" schematic of the implemented evaporator showing the headers

A more rigorous way to build a compact heat exchanger model would be to represent each plate with a dedicated 1-D pipe simulation block. Accuracy would be expected to increase, but the much increased simulation execution time reduces the practicality of this approach.

Routing the airflow is also relatively easy with the applied modeling methodology. The segment-wise exit air flow variables from a plate are passed as an output vector from the 1-D pipe simulation block representing the plate. This vector can be directly fed into the inlet air flow variables input port of the simulation block representing another plate in another downstream row/pass. For some cases this is done with a direct connection, for example, when the plates in the upstream row and in the downstream row are aligned and the refrigerant flow direction is the same in them (see pass 3 air exit flow to pass 1 air inlet flow). In other cases, the order of the passed air flow variables vector needs to be reversed (see pass 3 air exit flow to pass $2 \mathrm{a}$ air inlet flow).

Alternatively, the exit air flow output vector can be fed through another simulation block, the "mixing" block that calculates the flow properties of the mixed out stream. This option can be used for the last row of the heat exchangers where the airflow from the plate is also exiting the whole heat exchanger. The variables of the mixed out-flow are calculated from the variables of the individual pipe segment exit flows based on the conservation of mass and energy. Additional condensation may take place during the mixing, and it is accounted for in the calculation. The mixing block can also be used when the plates do not obviously align or different numbers of pipe segments are desired to be used in the different passes due to numerical stability considerations.

\section{Thermostatic Expansion Valve}

The expansion device implemented in the model is an externally balanced thermostatic expansion valve (TXV). Delayed response of the bulb temperature to changes in the evaporator exit temperature is achieved with a first-order delay simulation block. The characteristic time of this response is an input parameter to the model. The bulb pressure is the saturated pressure of the refrigerant at the bulb temperature.

This response is the only dynamically modeled detail. Otherwise, the position of the valve ball is determined from static force balance. The moving masses inside the TXV are so small that the characteristic time of the valve ball position response to changing pressures is very small. Some wave phenomenon may make a difference here; however, the model would not be very efficient if such detail is included the simulation time step would have to be very small. The input parameters that play into the TXV static force balance calculation include the spring preload, the spring rate, the ball diameter, ball seat angle, actuating pin diameter, and the bulb actuator diameter. Furthermore, the ball stroke limits the maximum opening area and can be adjusted for a given ton rating of the TXV.

Once the flow area through the flow restriction device of the valve is known, the refrigerant flow rate is calculated from the two-phase orifice flow equations. In addition to the flow area, the upstream conditions and the downstream pressure are used in this calculation. First the model determines the critical pressure, $p^{*}$, and critical unit area mass flow rate, $q^{*}$, from lookup tables, based on upstream pressure, $p_{u}$, and enthalpy, $h_{u}$ :

$$
\begin{aligned}
& p^{*}=p^{*}\left(p_{u}, h_{u}\right) \\
& q^{*}=q^{*}\left(p_{u}, h_{u}\right)
\end{aligned}
$$

These lookup tables were generated for R134a from other property tables with the conditions that the flow is isentropic 
between the inlet and the throat, and that the Mach number equals one in the throat for choked flow. Then the calculation of the mass flow rate, $q$, depends on whether the downstream pressure, $p_{d}$, is lower or higher than the critical pressure. If $p_{d}$ $\leq p^{*}$ (choked flow), the mass flow rate, $q$, is

$$
q=q^{*} \cdot A_{x} \cdot C_{d}
$$

where $A_{x}$ is the flow area in the throat and $C_{d}$ is the discharge coefficient. On the other hand, if $p_{d}>p^{*}$ (non-choked flow), the mass flow rate is calculated from the conditions that the flow is isentropic between the inlet and the throat, and that the enthalpy in the throat is the enthalpy at the inlet minus the flow kinetic energy at the throat (the steady state flow version of the energy equation with zero inlet kinetic energy assumption).

The equations implemented in the orifice model are valid for adiabatic one-dimensional homogeneous equilibrium twophase flow. However, adjustment was made to approximate some non-equilibrium effect. Data measured for short orifices was used for this purpose [14]. A discharge coefficient was determined as the ratio of the actual mass flow rate to the mass flow rate predicted by the above equilibrium calculation method. It was noticed that the discharge coefficient was a function of how far the upstream conditions deviated from saturated liquid conditions. Therefore, the discharge coefficient can be set as a function of $p_{r}$, the ratio of the upstream pressure and the saturated liquid pressure at upstream enthalpy:

$$
p_{r}=\frac{p_{u}}{p_{s a t}\left(h=h_{u}\right)}
$$

The success of this approach is demonstrated in Fig. 4a in which 40 short-orifice R134a flow data points with various upstream conditions and downstream pressures were plotted on the $p-h$ space, and the calculated discharge coefficients for each data point were plotted as a function of the variable $p_{r}$ in Fig. 4b. The correlation fit line that was developed and implemented in the model is shown in Fig. 4b. The orifice for this correlation was $1.22 \mathrm{~mm}$ in diameter and $13.1 \mathrm{~mm}$ long, and arguably quite different in shape from the inner details of the flow path in a TXV. However, there is a reasonable freedom built into the input parameter list of the TXV simulation block to adjust the shape of the $C_{d}\left(p_{r}\right)$ curve for TXV data that the user may have available.

Note that with proper selection of input parameter values, the TXV model can easily be reduced to an orifice tube model. No modification to the Simulink model is needed for this purpose.

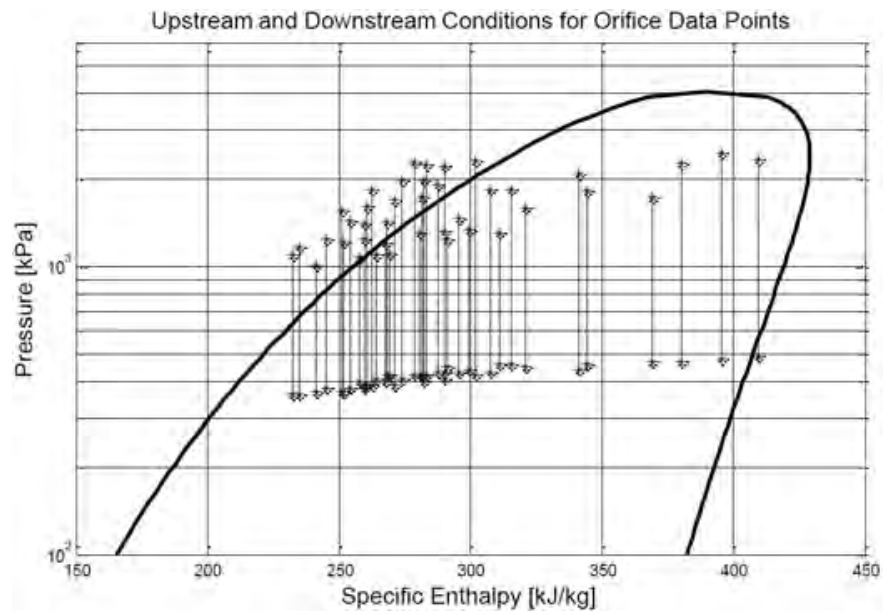

Fig. 4a. Short-orifice data points on p-H space

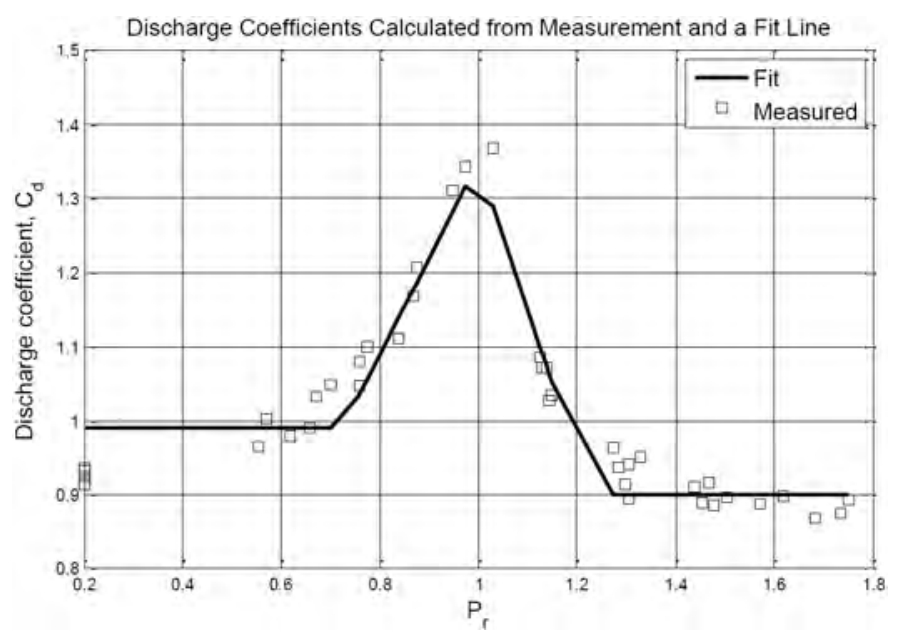

Fig. 4b. Calculated $C_{d}$ plotted against the variable $P_{r}$

\section{Compressor}

The compressor is a constant volume variable speed displacement device. The rotational speed and the displacement per revolution (both input parameters) determine the ideal forwarded volume per second. Actual forwarded volume per second is then obtained with the application of a volumetric efficiency. Upstream conditions and downstream pressure are input. The downstream enthalpy is calculated with the help of an isentropic efficiency ([15], Eq. 6-62).

Both the volumetric and the isentropic efficiencies are functions of the compressor speed and the downstream-toupstream pressure ratios. These tables are input to the model. There are two versions of the model, one for a mechanical and one for an electric drive compressor. The compressor efficiency tables are different for these model versions. For the mechanical drive compressor version, efficiency tables typical of a piston compressor were used. For the electric 
drive compressor version, efficiency tables typical of a scroll compressor were used.

Compressor cycling is accounted for, and there are certain controls implemented for that in the model (see Controls). These controls are different for mechanical and electric drive compressors.

Variable displacement compressors are gaining ground in mechanical drive $\mathrm{A} / \mathrm{C}$ systems as they have an additional degree of freedom in setting the refrigerant mass flow rate compared with a constant displacement device. This additional control reduces the need for the inefficient cycling of the compressor. It is easy for the model user to modify this compressor model to represent a variable displacement device. At this time, the effects of lubricating oil on the compressor - or the system as a whole - have not been accounted for.

\section{Cabin Model}

The cooling system model is enhanced with a cabin model. The purpose of the cabin model is to provide a reasonably accurate estimate of the cabin conditions that can serve as the boundary conditions for the cooling circuit model. The cabin air is represented with a zero-dimensional lump-sum air / water vapor mix volume. The cabin shell and interior thermal masses are included. Heat transfer between the thermal masses, the cabin air, and the ambient are accounted for, as well as the solar energy absorption by each thermal mass. The thermal masses and the heat transfer paths that are included in the model are shown in Fig. 5.

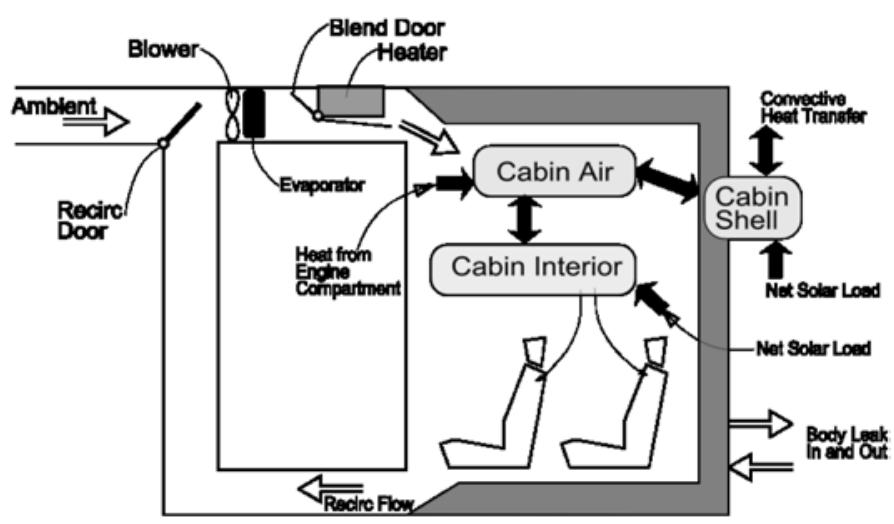

Fig. 5. Schematic of the cabin model

The thermal masses are shown in the rounded boxes, and the heat transfer paths are shown with solid arrows. All body air leak flow rates are lumped together and calculated as an adjustable constant times the pressure differential between the cabin and the ambient. The cabin model schematic is shown with the air passages for fresh and recirculated air.

\section{Controls}

Basic electronic controls have been implemented in the model. Shut-off of the compressor due to downstream pressure passing above a high pressure limit, or upstream pressure passing below a low pressure limit is included. Limits on how long the compressor has to stay off after each shut-down is also implemented. The cabin air recirculation rate is set based on whether the cabin temperature exceeds the outside temperature or not. Alternatively, the recirculation rate can be set constant over the entire simulation. These basic controls are implemented for both the mechanical and the electric drive compressor versions of the model.

In addition, for the model version with the mechanical drive compressor, the compressor is cycled on or off depending on whether the cabin temperature is below or above the target temperature and whether the evaporator-out air temperature is below or above a set target temperature (to prevent freezing). A temperature dead band is also implemented for both to reduce the frequency at which the cycling occurs. The evaporator blower speed is set to one of a number of settings at the beginning of the simulation and remains constant throughout the simulation.

On the other hand, in the model version with the electric drive compressor, where the compressor speed can be controlled independently of the vehicle's engine speed, the compressor speed is adjusted based on whether the evaporator wall temperature is above or below a set target in a region just upstream of where superheat is expected in the evaporator. This way, freezing of the evaporator can be avoided most of the time without having to cycle the compressor on and off. Unlike in the model with the mechanical drive compressor, the blower flow is adjusted based on the cabin temperature relative to the set cabin target temperature. There is an additional compressor cycling algorithm: if the controller would otherwise command bringing down the compressor RPM below a minimum, the compressor will cycle off. When the compressor restarts, it restarts at that same minimum RPM. This is done so that the compressor does not operate in the inefficient low RPM regime.

These controls are easily modified and additional control algorithms can be added by the user given the block simulation environment of Simulink. In fact, one of the best applications of this model may be the development of control systems for optimum $\mathrm{A} / \mathrm{C}$ system performance and efficiency. The fact that the model handles compressor shutdown and start-up transients robustly and at least in theory accurately, is an important feature of the model in this regard.

\section{Model Performance}

During development, it was an important goal that the model would run at an execution speed that is practical for the development of $\mathrm{A} / \mathrm{C}$ systems and in the evaluation of vehicle power management, for example, when used in cosimulation with Autonomie. The execution speed is dominated by the small time step required by the model to run successfully and to be free of unrealistic oscillations. In that regard, a $2 \mathrm{e}-5 \mathrm{sec}$ simulation time step was found to be the best for a typical automotive $\mathrm{A} / \mathrm{C}$ model, and with that, the execution speed is on the order of 10 times that of real 
time speed on a 64 bit Windows computer. It is certainly desirable to improve the execution speed, and current efforts are aimed to create versions of the model that trade some of the transient simulation accuracy for a much improved execution speed.

Execution speed is also dependent on the number of segments in the heat exchanger flat tubes or plates. In the current model, 18 segments for the condenser flat tubes and 10 segments for the evaporator plates were used. Fewer segments increase simulation speed due to both fewer operations per time step and the possibility of using larger time step, but at a cost of reduced accuracy.

Another measure of performance is how well the conservative variables are preserved. This is important because when highly transient processes for long simulation times are modeled a loss of refrigerant mass due to numerical inaccuracies may be experienced leading to unacceptable errors. The finite volume formulation implemented in the model preserves mass and energy of the refrigerant with high accuracy. Evaluating mass and energy conservation on the system level is relatively easily done and it provides a good check on the error free implementation of the governing equations. Momentum is lost as refrigerant enters the 0-D volumes from the 1-D pipes, so it is not usable in this regard on the system level.

To demonstrate the conservativeness of the model, data obtained with the mechanical drive compressor version for the 600 second long SC03 cycle were used (see the 'Results' section). To check on conservation of mass, the total refrigerant mass in the system was summed at the beginning and at the end, and the difference was less than $0.001 \%$. A similar check on the conservation of energy was also carried out. According to the First Law of Thermodynamics, the final total energy in the refrigerant must equal the initial total energy in the refrigerant plus the total energy transferred to the refrigerant via heat transfer and by the compressor work. The deviation, once again, turned out to be less than $0.001 \%$.

\section{VERIFICATION AND RESULTS}

\section{System Level Verification}

Measured data for calibration and verification are not easy to obtain as they are guarded by the component manufacturers. However, some limited calibration and verification of the model with the use of steady state performance data on an actual light-duty $\mathrm{A} / \mathrm{C}$ system have been carried out. Because the heat exchanger air inflow parameters were known and they were constant in time, the cabin model was essentially deactivated.

The data set used for verification included 22 steady-state operating points. The bench data included pressures and temperatures along the entire refrigerant circuit, properties of the upstream and downstream air streams on the heat exchangers, and the compressor speed and mass flow rate data. The evaporator superheat was measured, and the TXV model was set up for this nominal superheat. The internal details of the TXV used in the tests were not known, but did not matter for the calibration of the model for the rest of the system.

From the measured compressor mass flow rate and from the inlet and outlet refrigerant thermodynamic properties, the volumetric and isentropic efficiencies of the compressor were calculated as a function of compressor RPM and pressure ratio. When the simulation was carried out, the compressor RPM was set to the measured one. For a properly verified and calibrated model, the compressor performance had to converge to the measured pressure ratio and mass flow rate. Showing a good match between measured and predicted refrigerant mass flow rates over a significant range of operating points also verifies that it is acceptable to use volumetric and the isentropic efficiencies as functions of RPM and pressure ratio.

Uncertainty analysis for the measurements was not available; however, data on reproducibility provided a measure of the integrity of the data. The relative deviation of results between an original and a repeated test, averaged for six operating points, were $1.0 \%, 3.2 \%$ and $1.1 \%$, for evaporator heat transfer, compressor power and refrigerant mass flow rate, respectively. A source of inaccuracy in the validation process was the fact that lube oil was present in the measured system but was not accounted for in the simulation.

Since the actual geometry of the transport pipes connecting the $\mathrm{A} / \mathrm{C}$ components were not available, the model version used for the verification did not include the simulation blocks for the transport pipes. According to the measured data, refrigerant property changes over most transport pipes could be neglected except for the pipe connecting the evaporator outlet and the compressor inlet. The effect of the losses in this pipe on the system performance was simply represented by a pressure/enthalpy change simulation block between the evaporator refrigerant outlet and the compressor inlet.

With these constraints, all 22 measurement points were simulated, and some calibration was done on the heat transfer correlation coefficients. Note that the need for calibration is especially justified given that the evaporator plates utilized "dimples" to enhance the heat transfer rate and on the air side the presence of condensation most likely significantly altered the heat transfer rates compared to the Chang correlation. In Figs. 6.a and 6.b, the thermodynamic cycles for measurement points 4 and 6 , respectively, are shown on the pressureenthalpy space. These two points are representative of the full 22-point series in terms of the quality of the match, and the match between the simulation and the measurement is seen as quite good. 


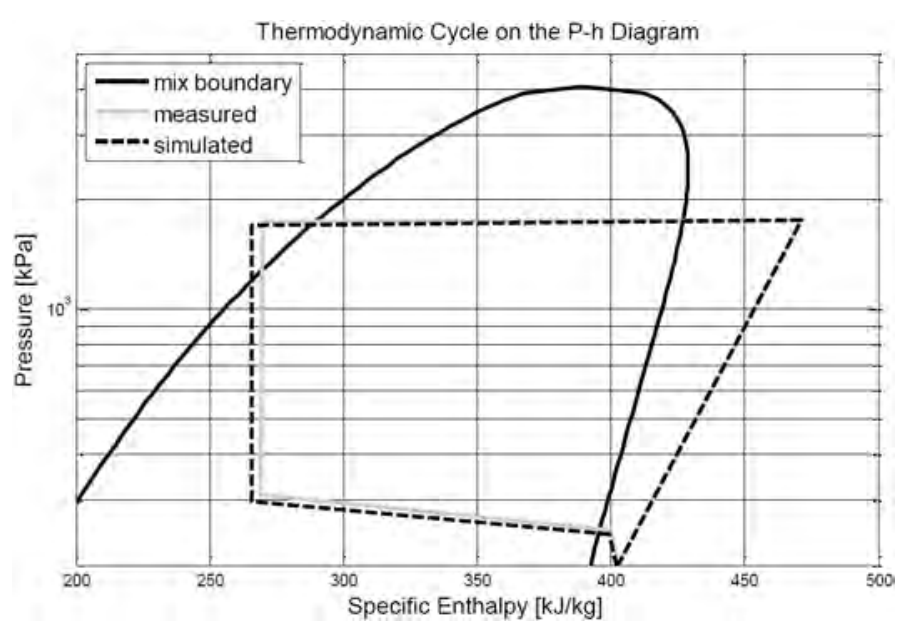

Fig. 6a. Thermodynamic cycle for Test Point 4

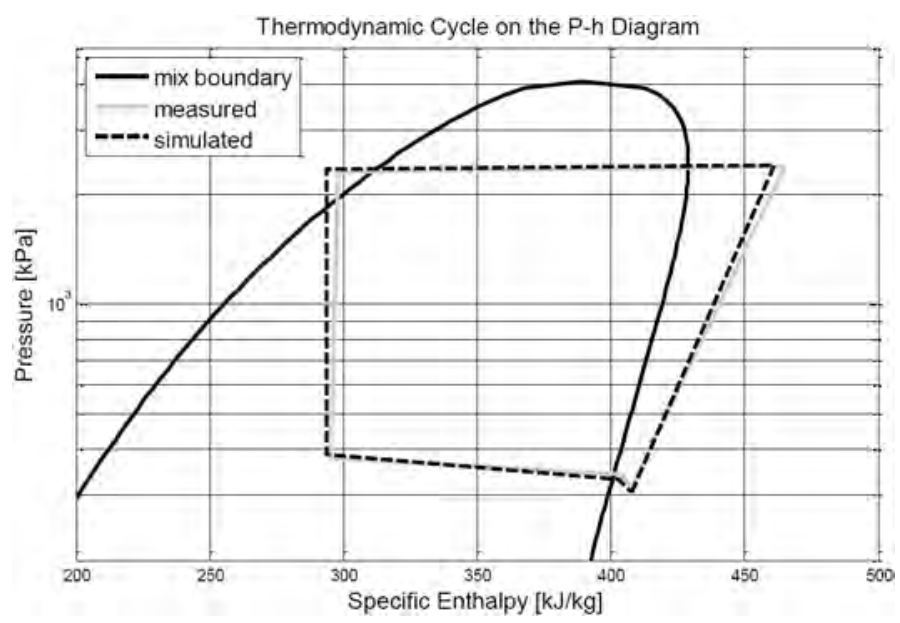

Fig. 6b. Thermodynamic cycle for Test Point 6

\section{Component Level Verification}

Four pieces of component data were also derived from each of the full cycle results. These include the refrigerant flow rate (constant through the system for the steady state points), the refrigerant-side heat transfer rate on the condenser, the refrigerant-side heat transfer rate on the evaporator, and the evaporator-out air temperature. The measured and simulated data for these four properties are included in Figs. 7a, $\underline{7 b}, \underline{7 c}$ and $\underline{7 d}$, respectively.

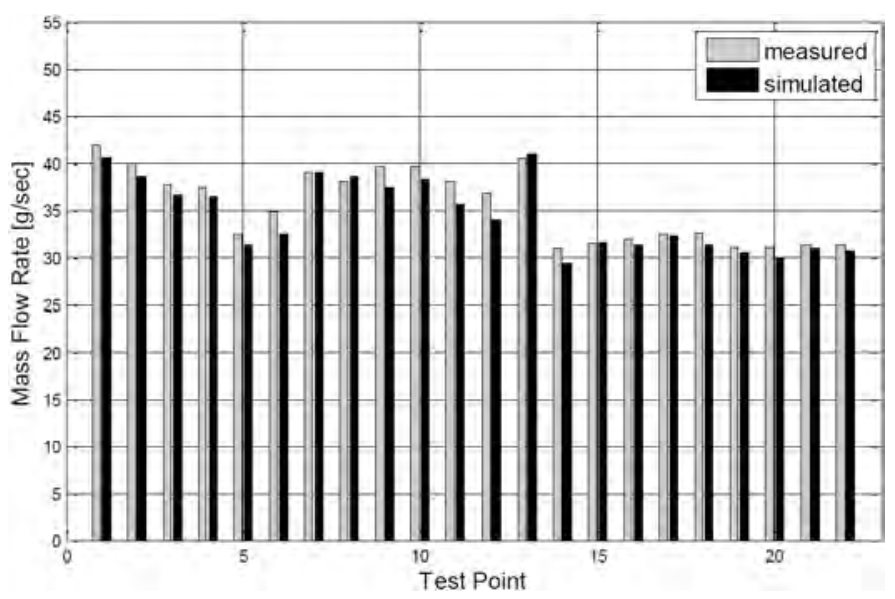

Fig. 7a. Predicted and measured compressor mass flow rate

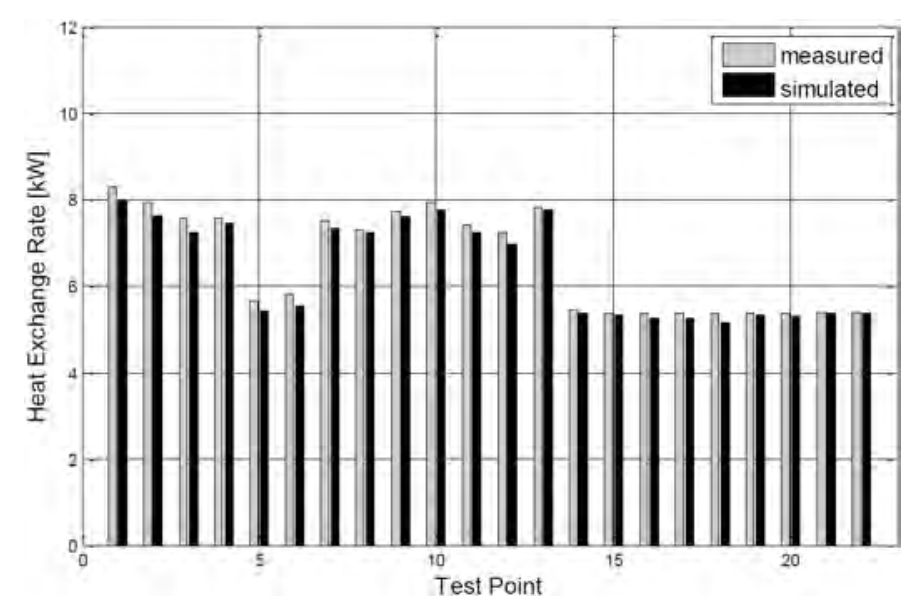

Fig. 7b. Predicted and measured condenser heat exchange rate

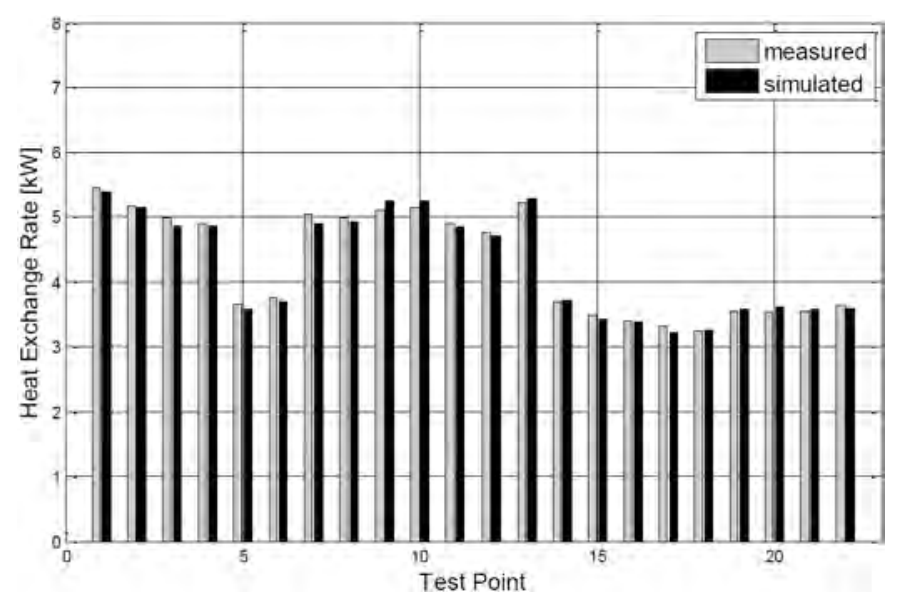

Fig. 7c. Predicted and measured evaporator heat exchange rate 


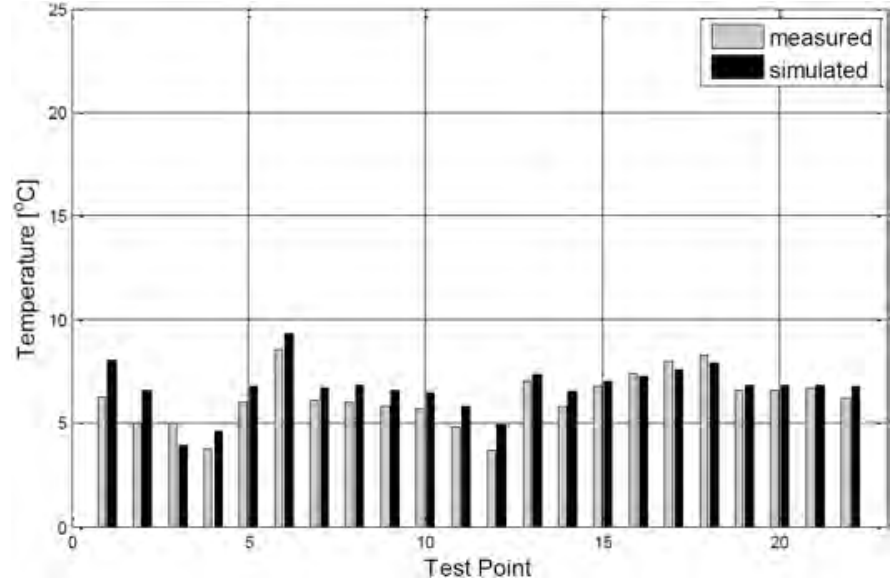

Fig. 7d. Predicted and measured evaporator air-out temperature

Figs. 7a, 7b, 7c and $7 \mathrm{~d}$ show that a good match between the measured and the simulated data was achieved. The average errors were $3.1 \%, 1.4 \%, 2.2 \%$ and $0.7^{\circ} \mathrm{C}$, respectively.

\section{Results}

The SC03 cycle was simulated with both the mechanical and the electric drive compressor versions of the model. The models were set up for the same system geometry and initial conditions. The results for the mechanical drive compressor are shown in Figs. 8a, $\underline{\mathrm{b}}, \underline{\mathrm{c}}$ and $\underline{\mathrm{d}}$, and the results for the electric drive compressor are shown in Figs. $9 \mathrm{a}, \underline{\mathrm{b}}, \underline{\mathrm{c}}$ and $\underline{\mathrm{d}}$.

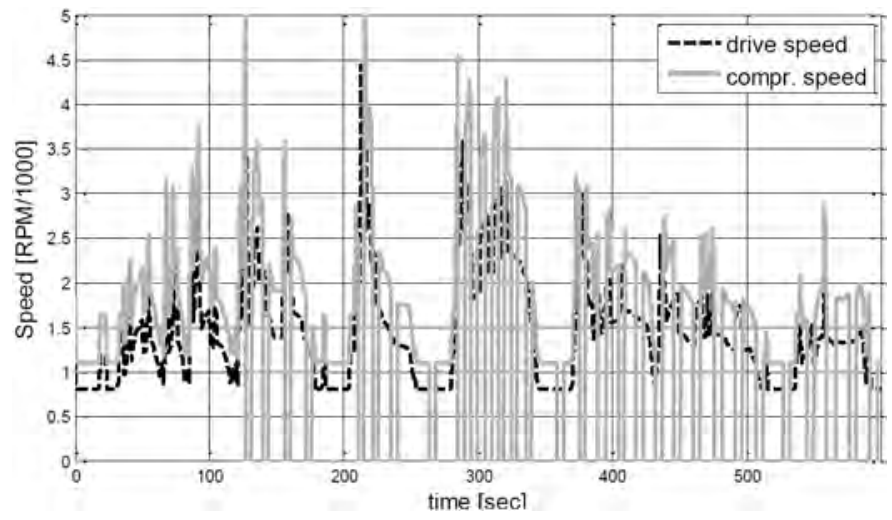

Fig. 8a. Compressor and drive speed, mechanical drive, SCO3 cycle

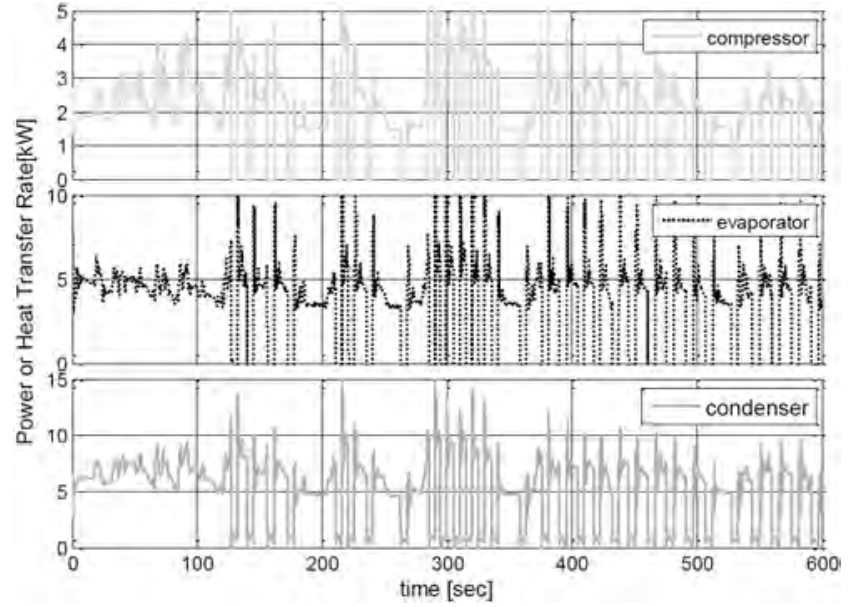

Fig. 8b. Compressor power and heat transfer rates mechanical drive, SCO3 cycle

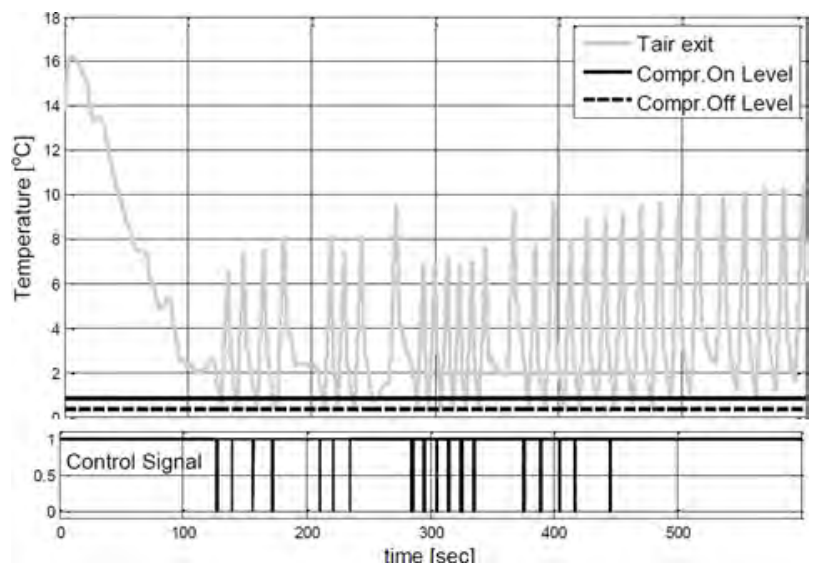

Fig. 8c. Evaporator air-out temperature with compressor switch limits and control signal, mechanical drive, SCO3 cycle

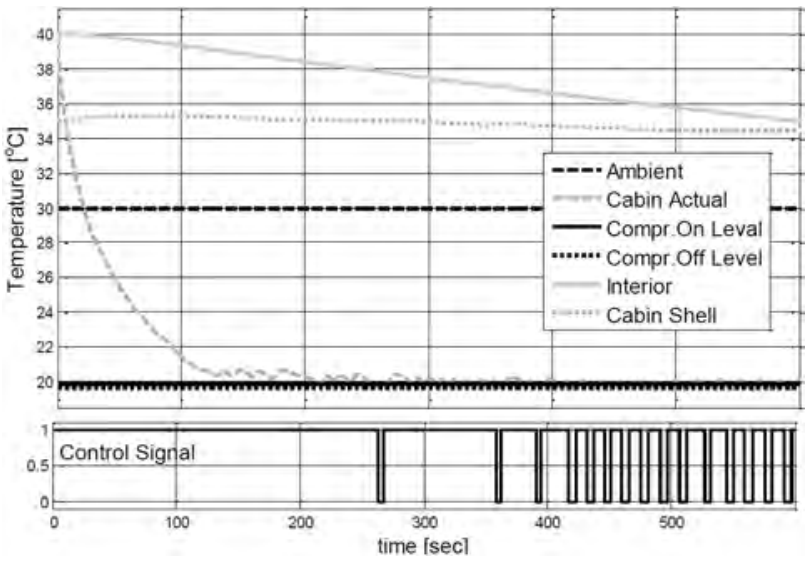

Fig. 8d. Cabin temperatures with compressor switch limits and control signal, mechanical drive, SC03 cycle 
Note that for the mechanical drive compressor, the compressor speed is either a pulley ratio times the drive speed, when the compressor is on, or zero, when the compressor is off. In Fig. 8c, the "Compr. On Level" is the temperature that the evaporator exit air temperature has to pass in the upward direction for a "compressor on" trigger, and the "Compr. Off Level" is a temperature slightly lower that the evaporator exit air temperature has to pass in the downward direction for a compressor off trigger. In Fig. 8d, the "Compr. On Level" is a temperature that the cabin air temperature has to pass in the upward direction for a "compressor on" trigger and the "Compr. Off Level" is a temperature that the cabin air temperature has to pass in the downward direction for a "compressor off" trigger.

Results for the $\mathrm{SC} 03$ cycle with the electric drive compressor A/C model (shown in Figs. 9a, $, 9 \mathrm{~b}, \underline{9 c}, \underline{9 d}$ ) are presented slightly differently as the controls are different. Note the lack of compressor cycling, which is achieved by a compressor speed that is independent of the engine speed. The evaporator wall temperature target was set at $3^{\circ} \mathrm{C}$, and the minimum for this temperature turned out to be $1.7^{\circ} \mathrm{C}$. The smooth compressor speed trace allows for significantly reduced transient spikes in most variables compared to the mechanical drive compressor $\mathrm{A} / \mathrm{C}$ model. For a different problem setup in which the target cabin temperature could be achieved with much lower average evaporator load, compressor cycling would be taking place as the compressor speed would be driven down to below the minimum allowed speed by the controller.

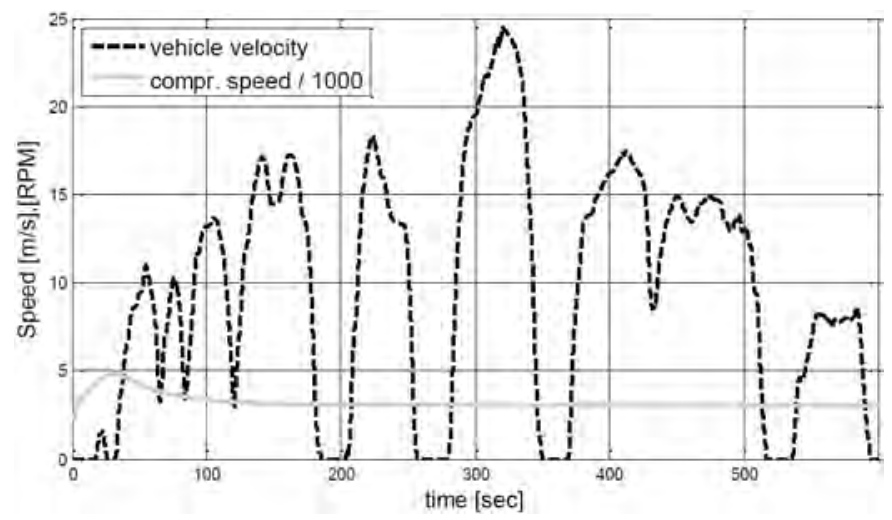

Fig. 9a. Vehicle velocity and scaled compressor speed. electric drive, SC03 cycle

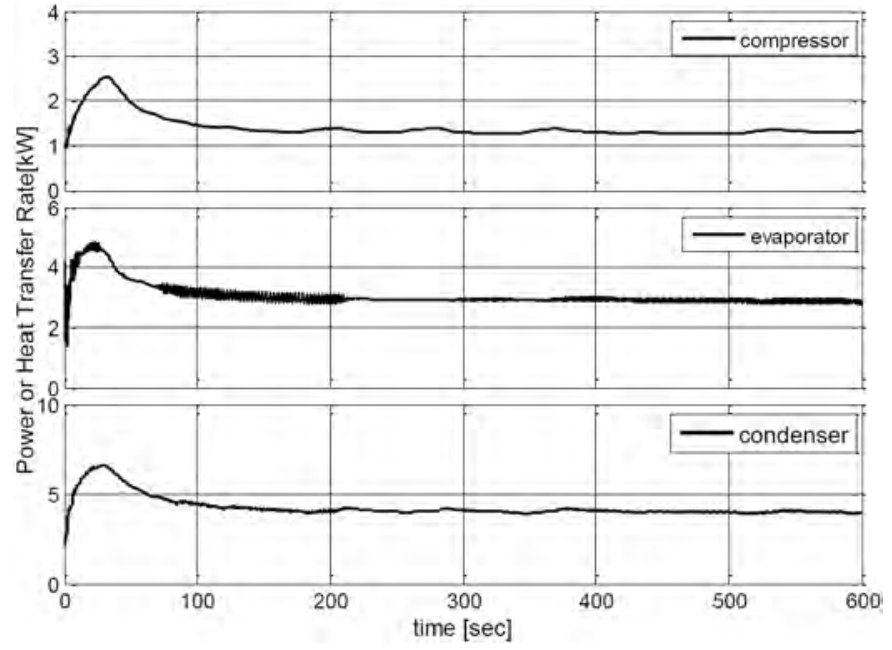

Fig. 9b. Compressor shaft power and heat transfer rates, electric drive, SC03 cycle

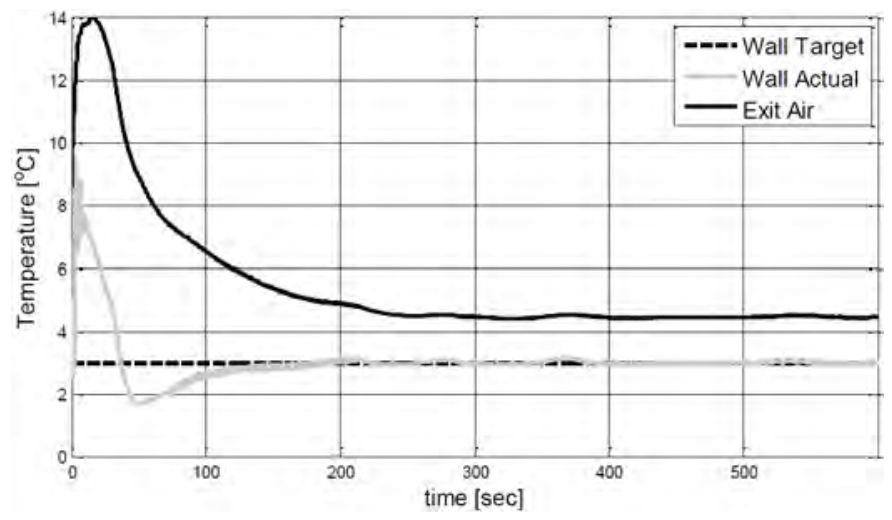

Fig. 9c. Evaporator temperatures, electric drive, SC03 cycle

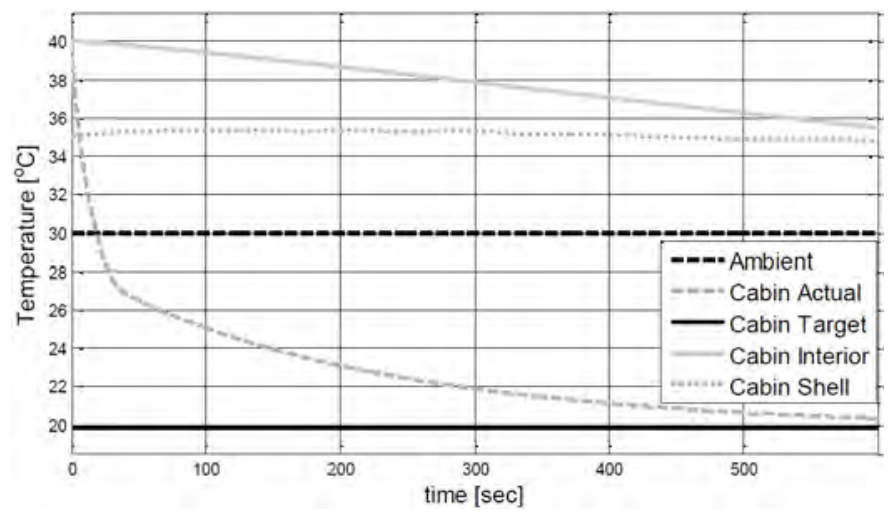

Fig. 9d. Ambient and cabin temperatures, electric drive, SC03 cycle 


\section{CONCLUSIONS}

A new automotive $\mathrm{A} / \mathrm{C}$ system simulation tool developed on the MATLAB/Simulink platform has been described. The model consists of a detailed cooling circuit model and a relatively simple cabin model. The governing equations for the key system simulation blocks have been provided. A finite volume formulation of the governing equations was used on the refrigerant side, which provided a very accurate preservation of refrigerant mass and a very accurate energy balance. The model can handle the fast transients that occur in an automotive $\mathrm{A} / \mathrm{C}$ system.

Comparison of simulated data with test data for a set of 22 steady state test points shows good agreement between simulation and measurement. For the refrigerant mass flow rate, the evaporator load, the condenser load, and the evaporator-out air temperature, the average errors were $3.1 \%$, $1.4 \%, 2.2 \%$ and $0.7^{\circ} \mathrm{C}$, respectively. Two main versions of the model exist at this time, one version with a mechanical drive compressor and the other with an electric drive compressor model. The main difference between the two versions is the method of electronic controls, and some results for both versions have been presented for the $\mathrm{SC} 03$ cycle. This model is well suited for co-simulation with vehicle system analysis software and for development of $\mathrm{A} / \mathrm{C}$ system controls for optimized system performance. The model is also expected to be a useful tool for designing automotive $\mathrm{A} / \mathrm{C}$ systems, although such use has not been demonstrated yet.

As a final note, the U.S. Environmental Protection Agency and the National Highway Traffic Safety Administration have recently published greenhouse gas (GHG) emission and fuel consumption regulations for 2012 2016 and for $2017-2025$ [16, 17]. These regulations include the acknowledgement that $\mathrm{A} / \mathrm{C}$ fuel consumption contributes significantly to overall vehicle GHG emissions. In an attempt to reduce this amount, a credit scheme is being implemented so that auto makers that employ highly efficient $\mathrm{A} / \mathrm{C}$ components are awarded GHG credits. While not an official tool, the model presented in this paper can be useful for evaluating the reduction in GHG emissions over any drive cycle that results from using more efficient air conditioning components. In this way the model can both aid regulators define credit amounts and assist car manufacturers in deciding among competing technologies.

\section{REFERENCES}

1. Rugh, J. P., Hoveland, V., and Andersen, S. O. "Significant Fuel Savings and Emission Reductions by Improving Vehicle Air Conditioning," Earth Technologies Forum/Mobile Air Conditioning Summit, 2004.

2. Umezu, K., and Noyama, H., "Air-Conditioning System for Electric Vehicles (i-MiEV)," SAE Automotive Alternate Refrigerant Systems Symposium, 2010.

3. National Renewable Energy Laboratory, Vehicle Technologies Program 2007 Annual Report, pp. 145

4. Stodolsky, F., Gaines, L., and Vyas, A. Analysis of Technology Options to Reduce the Fuel Consumption of Idling Trucks. Argonne National Laboratory, ANL/ESD-43, June 2000

5. Computer Software "Autonomie", www.autonomie.org
6. Hemami, T. L., "Development of a Transient System Model of Mobile Air-Conditioning Systems," ACRC Technical Report - 143, September 1998.

7. Cullimore, B. A., and Hendricks, T. J., "Design and Transient Simulation of Vehicle Air Conditioning Systems," VTMS 5 2001-01-1692

8. Anand, G., Mahajan, M., Jain, N., Maniam, B. et al., "e-Thermal: Automobile Air-Conditioning Module," SAE Technical Paper 2004-01-1509, 2004, doi:10.4271/2004-01-1509.

9. Streeter, V.L., and Wylie, E.B., "Fluid Mechanics" $7^{\text {th }}$ edition, McGraw-Hill, 1979.

10. Incropera, F., P., and DeWitt, D.P., "Fundamentals of Heat and Mass Transfer," $2^{\text {nd }}$ edition, 1985, John Wiley and Sons, Inc.

11. Chen, J.C. "Correlation for Boiling Heat Transfer to Saturated Fluids in Convective Flow," I\&EC Process Design and Development, Vol. 5. No. 3 July 1966 pp. 322 - 329.

12. Morales-Ruiz, S., Rigola, J., Perez-Segarra, C.D., and GarciaValladeres, O., "Numerical Analysis of Two-Phase Flow in Condensers and Evaporators with Special Emphasis on Single-Phase/Two-Phase Transition Zones," Applied Thermal Engineering, 2009 Volume 29, pp. $1032-1042$.

13. Chang, Y., and Wang, C., "A Generalized Heat Transfer Correlation for Louver Fin Geometry," Int. J. Heat and Mass Transfer, vol. 40, No. 3 , pp. 533-544, 1997.

14. Singh, G.M., Hrnjak, P.S., and Bullard, C.W., "Flow of Refrigerant 134a Through Orifice Tubes," HVAC\&R Research, Vol. 7, No.3, pp. 245-262, July 2001.

15. Cengel, Y.A., and Boles, M.A., "Thermodynamics - An Engineering Approach," McGraw-Hill, 1994.

16. Federal Register, May 7, 2010.

17. Federal Register, August 28, 2012.

\section{CONTACT INFORMATION}

Tibor Kiss

tibor.kiss@nrel.gov

Lawrence Chaney

lawrence.chaney@nrel.gov

Jason Lustbader

jason.lustbader@nrel.gov

\section{ACKNOWLEDGMENTS}

The authors would like to thank John Rugh and Jason Lustbader of NREL for their contribution to this project.

The authors would also like to thank Lee Slezak and David Anderson, Technology Managers for the U.S. Department of Energy's Advanced Vehicle Technology Analysis and Evaluation for sponsoring this work.

\section{DEFINITIONS/ABBREVIATIONS}

A/C - Air Conditioning

EV - Electric Vehicle

OEM - Original Equipment Manufacturer

NREL - National Renewable Energy Laboratory

0-D - Zero Dimensional

1-D - One-Dimensional

TXV - Thermostatic Expansion Valve

RPM - Revolution per minute

GHG - Green House Gases 